\title{
Wettability of crushed air-dried minerals
}

\author{
S. D. N. LOURENÇO*, S. K. WOCHE†, J. BACHMANN† and Y. SAULICK*
}

\begin{abstract}
The importance of soil particle wettability has been recognised in mining engineering, soil science and geomorphology but to a lesser extent in geotechnical engineering, perhaps due to the assumption that soils, or in general most common minerals, are always wettable. From the soil science and geomorphology literature, changes in soil wettability are known to influence soil processes such as infiltration, erosion and post-wildfire debris flows. Organic matter has been identified as one of the most important factors controlling the wettability of natural soils. However, its occurrence is very shallow and often shallower than the depth of interest for geotechnical processes. Therefore, it becomes essential to determine the wettability of minerals, in particular because it can be linked to processes that involve crushing or abrasion of soil particles. This paper examines the wettability of 21 common, freshly crushed minerals (sulfides, oxides and silicates) by measuring wettability via contact angles with the sessile drop method and the Wilhelmy plate method, including particle attributes such as aspect ratio and sphericity. The results revealed a wide range of contact angles for the uncoated minerals, with the sulfides showing strong water-repellent behaviour and the silicates remaining very wettable. Higher contact angles are associated with mineral particles that converge to the shape of a sphere and for those that have a larger aspect ratio.
\end{abstract}

KEYWORDS: chemical properties; geology; microscopy; particle-scale behaviour

ICE Publishing: all rights reserved

\section{INTRODUCTION}

Commonly occurring minerals are expected to be wettable because the surface free energy of unweathered inorganic soil particles is generally higher than that of water, with an apparent contact angle (CA) of $0^{\circ}$. Mineral engineering has shown some exceptions (e.g. sulfide minerals such as galena or pyrite) that are strongly water repellent (e.g. Prestidge \& Ralston, 1995) while commonly occurring minerals such as quartz and calcite are wettable, but with CAvalues that differ from each other and are higher than the commonly assumed $0^{\circ}$ (Hajnos et al., 2013). In the long term, environmental factors may lead to a degradation of mineral surfaces, resulting in changes in wettability. Importantly, particle coatings with organic matter remain the most relevant contributor to soil water repellency (Ma'shum et al., 1988; Doerr et al., 2000).

In natural soils, water repellency impacts hydraulic behaviour, from reduced infiltration and surface runoff (Doerr et al., 2000; Jarvis et al., 2008) to preferential flow (Ritsema \& Dekker, 1996). In geotechnical applications, soil wettability is important because suction in unsaturated soils depends not only on the degree of saturation but also on the surface tension and the CAs of the water menisci. Regarding the mechanics and hydraulics of water-repellent soils, the internal friction angle is not affected in wax-coated sands (Bardet et al., 2011) but is reduced in synthetic waterrepellent soils (Byun et al., 2011). Soil water retention is reduced for soils with low wettability (Lourenço et al., 2015).

Several soil wettability determination methods have been developed and tested in soil science (e.g. Bachmann et al.,

Manuscript received 2 June 2015; first decision 25 June 2015; accepted 20 July 2015.

Published online at www.geotechniqueletters.com on 18 August 2015.

*Department of Civil Engineering, The University of Hong Kong, Hong Kong SAR

$\dagger$ Institute of Soil Science, Leibniz University Hannover, Germany
2003). They operate on different working principles and measure dynamic or static CAs using different sample preparation methods. The sessile drop method (SDM) and the Wilhelmy plate method (WPM), which measure CAs for the entire range from $0^{\circ}$ to $>90^{\circ}$ for samples from similar preparation methods, are considered here.

Given the fundamental importance of wettability to geotechnical processes that involve clean mineral particles generated by crushing or abrasion, a comprehensive study of mineral wettability is needed. In this work, the wettability of samples of crushed minerals from three major groups (silicates, oxides and sulfides) was measured using both the SDM and WPM. In particular, the wettability of the minerals (with no particulate organic matter) and the effect of the crushed mineral shape were investigated.

\section{MATERIALS AND METHODS \\ Minerals}

A set of commonly occurring minerals and rocks was selected from the mineral collection of Cardiff University, UK (Table 1). The selected minerals were grouped into silicates such as quartz and feldspar (among the most common in soils), oxides such as hematite and cassiterite (a by-product of chemical weathering) and sulfides (mineral ores from specific geological settings) (Table 1). The crushed rocks represent an assemblage of different minerals.

Mineral samples of mass 50-100 g were cleaned, cut into slices of $\sim 1 \mathrm{~cm}$ thickness, washed with deionised water to remove dust, allowed to dry at a temperature of $30^{\circ} \mathrm{C}$ (because the water repellency of natural soils is temperature dependent (Diehl et al., 2014)) and then crushed in a jaw crusher. The resulting material was gravel-sized, and therefore unsuitable for CA measurements. To reduce the size further, sub-samples were crushed in a ball mill (Retsch PM 400; Haan, Germany). Both the jaw crusher and the mill were cleaned with acetone before use. Lastly, the minerals 
Table 1. Mineral composition, particle attributes and CAs determined by SDM and WPM for the tested minerals, ranked in descending order of initial SDM CA

\begin{tabular}{|c|c|c|c|c|c|c|c|c|c|c|c|c|c|c|c|c|}
\hline \multicolumn{3}{|l|}{ Material } & \multicolumn{6}{|c|}{ Particle attributes } & \multicolumn{7}{|c|}{ CA: degrees } & \multirow{3}{*}{$\begin{array}{c}\text { WDPT: s } \\
n=3\end{array}$} \\
\hline \multirow[t]{2}{*}{ Name } & \multirow[t]{2}{*}{ Composition } & \multirow[t]{2}{*}{ Category } & \multirow[t]{2}{*}{ Size: $\mu \mathrm{m}$} & \multirow{2}{*}{$\begin{array}{l}\text { Number } \\
\text { of images } \\
\text { analysed }\end{array}$} & \multirow[t]{2}{*}{ Sphericity } & \multirow[t]{2}{*}{ SD } & \multirow[t]{2}{*}{ Aspect ratio } & \multirow[t]{2}{*}{ SD } & \multicolumn{6}{|c|}{ SDM } & \multirow[t]{2}{*}{ WPM } & \\
\hline & & & & & & & & & $\begin{array}{c}\text { Initial } \\
n=6\end{array}$ & SD & $\begin{array}{c}1 \mathrm{~s} \\
n=6\end{array}$ & SD & $\begin{array}{c}5 \mathrm{~s} \\
n=6\end{array}$ & SD & & \\
\hline $\begin{array}{c}\text { Minerals } \\
\text { Galena }\end{array}$ & & Sulfide & $<250$ & 33098 & $0.750^{\mathrm{b}}$ & & & & & & & & & & & \\
\hline Malachite & $\mathrm{Cu}_{2} \mathrm{CO}_{3}(\mathrm{OH})_{2}$ & $\begin{array}{l}\text { Sulfide } \\
\text { Carbonate }\end{array}$ & $\begin{array}{l}<250 \\
<250\end{array}$ & $\begin{array}{l}33098 \\
42004\end{array}$ & $\begin{array}{l}0.759^{\circ} \\
0.722^{b}\end{array}$ & $\begin{array}{l}0.06 \\
0.05\end{array}$ & $0.893^{\mathrm{b}}$ & $\begin{array}{l}0.13 \\
0.13\end{array}$ & $\begin{array}{l}131.6 \\
125 \cdot 4\end{array}$ & $\begin{array}{l}4 \\
4 \cdot 6\end{array}$ & $\begin{array}{l}130 \cdot 6 \\
125 \cdot 4\end{array}$ & $\begin{array}{l}3.6 \\
3.5\end{array}$ & $\begin{array}{l}151 \cdot 1 \\
124 \cdot 7\end{array}$ & $\begin{array}{l}3.1 \\
3.7\end{array}$ & $\begin{array}{l}164 \cdot 3 \\
150 \cdot 5\end{array}$ & $\begin{array}{l}\text { Permanent } \\
\text { Permanent }\end{array}$ \\
\hline Sphalerite & $(\mathrm{Zn}, \mathrm{Fe}) \mathrm{S}$ & Sulfide & $<250$ & 42940 & $0.723^{\mathrm{b}}$ & 0.06 & $0.887^{\mathrm{b}}$ & $0 \cdot 12$ & $124 \cdot 3$ & $5 \cdot 7$ & $116 \cdot 4$ & $7 \cdot 7$ & $111 \cdot 8$ & $6 \cdot 6$ & $120 \cdot 1$ & 30 \\
\hline Iron oxide & & Oxide & $125-250$ & 18927 & $0 \cdot 703$ & $0 \cdot 06$ & 0.841 & $0 \cdot 13$ & $99 \cdot 9$ & $5 \cdot 6$ & $84 \cdot 7$ & $11 \cdot 8$ & $77 \cdot 9$ & $10 \cdot 1$ & $96 \cdot 1$ & 0 \\
\hline Pyrite & $\mathrm{FeS}_{2}$ & Sulfide & $<250$ & 45442 & $0.697^{\mathrm{b}}$ & 0.07 & $0.875^{\mathrm{b}}$ & $0 \cdot 13$ & $99 \cdot 5$ & 3.8 & $95 \cdot 3$ & $7 \cdot 1$ & $87 \cdot 3$ & $7 \cdot 4$ & $112 \cdot 2$ & Permanent ${ }^{\mathrm{c}}$ \\
\hline Tourmaline & $\mathrm{XY}_{3} \mathrm{Z}_{6}\left(\mathrm{~T}_{6} \mathrm{O}_{18}\right)\left(\mathrm{BO}_{3}\right)_{3} \mathrm{~V}_{3} \mathrm{~W}$ & Silicate & $<250$ & $\mathrm{NM}^{\mathrm{a}}$ & NM & NM & NM & NM & $98 \cdot 8$ & $3 \cdot 5$ & $83 \cdot 1$ & $4 \cdot 3$ & $76 \cdot 4$ & $4 \cdot 8$ & $101 \cdot 7$ & NM \\
\hline Hematite & $\mathrm{Fe}_{2} \mathrm{O}_{3}$ & Oxide & $<250$ & 3754 & 0.458 & $0 \cdot 11$ & 0.750 & $0 \cdot 18$ & $84 \cdot 9$ & $6 \cdot 3$ & $58 \cdot 2$ & $14 \cdot 8$ & $48 \cdot 8$ & $14 \cdot 9$ & $73 \cdot 5$ & 0 \\
\hline Cassiterite & $\mathrm{SnO}_{2}$ & Oxide & $<250$ & 14044 & $0 \cdot 662$ & 0.07 & $0 \cdot 824$ & $0 \cdot 14$ & 58.9 & $12 \cdot 2$ & 33 & $11 \cdot 2$ & $25 \cdot 1$ & $9 \cdot 9$ & $64 \cdot 1$ & 0 \\
\hline $\begin{array}{l}\text { Calcite } \\
\text { Cas }\end{array}$ & $\mathrm{CaCO}_{3}$ & Carbonate & $<250$ & 27830 & 0.656 & 0.08 & 0.826 & $0 \cdot 14$ & $54 \cdot 7$ & 3 & 0 & 0 & 0 & 0 & $31 \cdot 1$ & 0 \\
\hline Biotite & $\mathrm{K}(\mathrm{Mg}, \mathrm{Fe})_{3} \mathrm{AlSi}_{3} \mathrm{O}_{10}(\mathrm{~F}, \mathrm{OH})_{2}$ & Silicate (mica) & $<250$ & 22402 & $0 \cdot 585$ & $0 \cdot 11$ & $0 \cdot 772$ & $0 \cdot 17$ & $44 \cdot 2$ & $7 \cdot 2$ & $24 \cdot 3$ & $4 \cdot 7$ & $14 \cdot 7$ & $5 \cdot 5$ & $31 \cdot 5$ & 0 \\
\hline Olivine & $(\mathrm{Mg}, \mathrm{Fe})_{2} \mathrm{SiO}_{4}$ & Silicate & $<250$ & NM & NM & NM & NM & NM & $32 \cdot 9$ & 8 & 0 & 0 & 0 & NM & $11 \cdot 2$ & 0 \\
\hline Amethyst & $\mathrm{SiO}_{2}$ & Silicate & $<250$ & 16511 & 0.634 & 0.08 & 0.811 & $0 \cdot 15$ & $27 \cdot 6$ & $5 \cdot 7$ & 0 & 0 & 0 & 0 & 0 & 0 \\
\hline Feldspar & $\mathrm{KAlSi}_{3} \mathrm{O}_{8}$ & Silicate & $<250$ & 32109 & 0.629 & 0.08 & 0.813 & $0 \cdot 14$ & $17 \cdot 2$ & 0 & 0 & 0 & 0 & 0 & 0 & 0 \\
\hline Quartz 2 & $\mathrm{SiO}_{2}$ & Silicate & $<250$ & $\mathrm{NM}$ & NM & NM & NM & NM & $\mathrm{NM}$ & NM & NM & NM & NM & NM & $5 \cdot 5$ & 0 \\
\hline Quartz 1 & $\mathrm{SiO}_{2}$ & Silicate & $<250$ & NM & NM & NM & NM & NM & 0 & 0 & 0 & 0 & 0 & 0 & 18 & 0 \\
\hline \multicolumn{17}{|l|}{ Rocks } \\
\hline Sandstone & - & Sedimentary rock & $<250$ & 32087 & $0 \cdot 764$ & $0 \cdot 05$ & $0 \cdot 892$ & $0 \cdot 12$ & 78.5 & $5 \cdot 5$ & $64 \cdot 5$ & $6 \cdot 1$ & $49 \cdot 8$ & $7 \cdot 4$ & $92 \cdot 3$ & $10 \cdot 5$ \\
\hline Bauxite $^{\mathrm{d}}$ & - & $\mathrm{Al}$ ore & $<250$ & $\mathrm{NM}$ & NM & NM & NM & NM & $42 \cdot 4$ & $14 \cdot 4$ & 0 & 0 & 0 & 0 & $31 \cdot 8$ & NM \\
\hline Breccia & - & Sedimentary rock & $<250$ & 39535 & $0 \cdot 670$ & 0.06 & 0.836 & $0 \cdot 13$ & NM & NM & NM & NM & NM & NM & $34 \cdot 3$ & NM \\
\hline Granite & - & Igneous rock & $<250$ & 99596 & 0.655 & 0.07 & 0.824 & $0 \cdot 14$ & NM & NM & NM & NM & NM & NM & $17 \cdot 9$ & NM \\
\hline
\end{tabular}

${ }^{a}$ Not measured

${ }^{\mathrm{b}}$ Particle aspect ratio and sphericity measured in $63-165 \mu \mathrm{m}$ sized particles

c Times exceeding $3 \mathrm{~h}$ listed as 'permanent'
d Bauxite is a chemical weathering by-product of certain rock types 
were sieved (mesh size of $250 \mu \mathrm{m}$ ) and sealed in plastic bags to avoid contamination.

\section{Sessile drop method}

To determine the CA, samples were fixed with double-sided adhesive tape on a glass slide as a monolayer of air-dried minerals (particle size $<250 \mu \mathrm{m}$ ). It should be noted here that the CA in soils is usually referred to as an apparent $\mathrm{CA}$, as it takes into account the material chemistry, roughness and other effects, and has to be distinguished from the intrinsic CA (related only to material chemistry). Each slide was placed on the CCD equipped contact angle microscope stage (OCA15; DataPhysics Instruments $\mathrm{GmbH}$, Filderstadt, Germany) and a water drop $(1 \mu \mathrm{l})$ of deionised water was placed onto the sample surface while recording the sequence by video (Goebel et al., 2013). Using SCA 20 software (DataPhysics, Filderstadt, Germany), the CA was obtained from the tangent to the point of the three-phase contact. To assess the time dependency of wettability, the CA was measured from the same video sequence after $30 \mathrm{~ms}$, 1 and $5 \mathrm{~s}$ of placement of the drop. For each sample, measurements were conducted for six water drops at room temperature $\left(20 \pm 1^{\circ} \mathrm{C}\right)$. The water drop penetration time (WDPT), an index test, was also determined to assess the time decay of water repellency by placing a $60 \mu 1$ drop on the surface of a bulk sample and timing its penetration (Doerr et al., 2006).

\section{Wilhelmy plate method}

A glass slide of area $3 \cdot 1 \mathrm{~cm}^{2}$ was covered with double-sided adhesive tape on all sides followed by a single-grain layer of air-dried minerals. The glass slide was attached to an electronic balance hanging vertically and gradually immersed into water, with the total force $\boldsymbol{F}_{\mathrm{t}}$ (in $\mathrm{N}$ ) acting on the plate given by Bachmann et al. (2003)

$$
\boldsymbol{F}_{\mathrm{t}}=W-\boldsymbol{F}_{\mathrm{b}}+\boldsymbol{F}_{\mathrm{w}}=W-V \rho \boldsymbol{g}+l_{\mathrm{w}} \sigma_{\mathrm{lv}} \cos \theta
$$

where $W(\mathrm{~kg})$ denotes the mass of the plate, $\boldsymbol{F}_{\mathrm{b}}(\mathrm{N})$ is the buoyancy force, $\boldsymbol{F}_{\mathrm{w}}(\mathrm{N})$ is the wetting force, $V\left(\mathrm{~m}^{3}\right)$ is the volume of plate immersed, $\theta$ (degrees) is the CA, $\sigma_{\mathrm{lv}}(\mathrm{mN} / \mathrm{m})$ is the surface tension of the liquid, $\boldsymbol{g}\left(\mathrm{m} / \mathrm{s}^{2}\right)$ is acceleration due to gravity, $\rho\left(\mathrm{Mg} / \mathrm{m}^{3}\right)$ is liquid density and $l_{\mathrm{w}}(\mathrm{m})$ is the wetted length of the sample. If the balance is tared, equation (1) can be rearranged to yield the advancing CA as

$$
\cos \theta=\frac{\boldsymbol{F}_{\mathrm{t}}+V \rho \boldsymbol{g}}{l_{\mathrm{w}} \sigma_{\mathrm{lv}}}
$$

For evaluation of the advancing CA $(\theta)$, the wetting force $\left(\boldsymbol{F}_{\mathrm{w}}\right)$ has to be determined through linear regression of the recorded weight curve as a function of immersion depth and by extrapolation to zero-depth immersion for $\boldsymbol{F}_{\mathrm{I}}$ (Bachmann et al., 2003). The CAs were measured using a tensiometer (DCAT 11; DataPhysics, Filderstadt, Germany) with an accuracy of $\pm 5^{\circ}$. One test was conducted for each mineral.

\section{Particle attributes}

A dynamic image analyser (QICPIC; Sympatec GmbH, Clausthal-Zellerfeld, Germany) was used to determine the particle attributes. The device comprises a gravity dispenser (GRADIS) and a feeding device (VIBRI) that controls the number of particles in contact with the laser beam per unit time. A series of frames is then captured by means of a camera from which different size and shape descriptors are extracted. The feed and frame rate were adjusted to $15 \%$ and $250 \mathrm{~Hz}$, respectively.

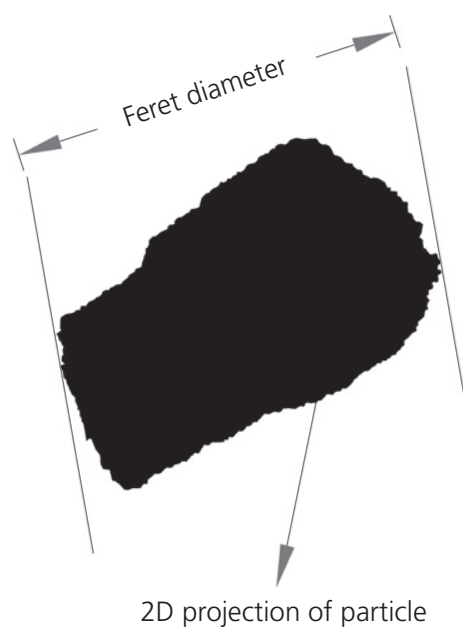

Fig. 1. Definition of Feret diameter from 2D profile

The aspect ratio as defined by QICPIC is the ratio of minimum to maximum Feret diameters, varying between 0 and 1. The Feret diameter is the length between two parallel lines tangential to a particle's silhouette (Fig. 1). The value of sphericity $(S)$ is the ratio of perimeters for a given area (equation (3)) and is equivalent to the 'degree of circularity' defined by Wadell (1933)

$$
S=\frac{P_{\text {eqpc }}}{P_{\text {real }}}
$$

in which $P_{\text {eqpc }}$ is the perimeter of the equivalent circle and $P_{\text {real }}$ is the actual perimeter. From equation (3), it can be deduced that the more the particle's two-dimensional (2D) outline deviates from a circle, the larger $P_{\text {real }}$ is. Thus, values of $S$ approaching unity correspond to a shape close to a sphere.

\section{RESULTS AND DISCUSSION}

Table 1 shows the CAs for the crushed materials ranked from highest to lowest. The CAs cover a large range, from $164 \cdot 3^{\circ}$ for galena to $0^{\circ}$ for quartz. The CAs can be arranged into three groups.

- The sulfides, together with malachite, achieved the highest $\mathrm{CA}\left(>99^{\circ}\right)$ with galena consistently achieving the greatest SDM and WPM CAs $\left(>130 \cdot 6^{\circ}\right)$ and pyrite the lowest $\left(87 \cdot 3^{\circ}\right)$. This strong water-repellent behaviour was stable over time, as confirmed by the WDPT with the drops in place after $3 \mathrm{~h}$.

- The oxides, together with tourmaline, revealed some water repellency, with CAs ranging between $58.9^{\circ}$ (cassiterite) and $99.9^{\circ}$ (iron oxide) but dropping to the order of $25^{\circ}$ for all oxides after $5 \mathrm{~s}$.

- All silicates, together with calcite, were strongly wettable with initial CAs of the order of $0^{\circ}$ (quartz) to $54.7^{\circ}$ (calcite).

The CA trends - higher for the sulfides, intermediate for the oxides and lower for the silicates - generally agree with the literature, albeit not in magnitude. For example, for sulfides, Prestidge \& Ralston (1995) and Subrahmanyam et al. (1996) measured CAs lower than $90^{\circ}$ using methods based on capillary pressure equilibrium. Reasons for the discrepancies include oxidation with time of the crushed sulfide surfaces (Prestidge \& Ralston, 1996), use of equilibrium CAs for the capillary pressure equilibrium methods, which are always lower than advancing CAs (Prestidge \& Ralston, 1995, 1996; Subrahmanyam et al., 1996) and measurements taken on flat 
surfaces, which minimises roughness (Raichur et al., 2001). The high CA of malachite is little documented, with Carr (1948) obtaining values in the range $50-90^{\circ}$ using different liquids. Maximum CAs for oxides have been reported as $80^{\circ}$, but higher for limonite $\left(\sim 90^{\circ}\right)$ (Maeda et al., 2008) and $74^{\circ}$ for hematite and goethite (Iveson et al., 2004). The reported CAs for silicates are generally low, matching this study $-30^{\circ}$ for quartz (Fisher \& Lark, 1980), 5.6-7.6 for dolomite (a carbonate) (Gence, 2006) and $10^{\circ}$ for mica (Bryant et al., 2006). In natural soils, which comprise mineral particles and organic matter, Hajnos et al. (2013) reported CAs in the range $2 \cdot 0-51 \cdot 8^{\circ}$ with the SDM technique.

The CAs were also correlated with particle shape, with more spherical particles achieving higher CAs. The particles' aspect ratios increased from 0.813 to 0.905 and their sphericity from 0.629 to 0.759 for WPM CAs of $0^{\circ}$ to $164^{\circ}$ (Fig. 2(a)). For the SDM, sphericity increased from 0.813 to 0.875 and aspect ratio from 0.629 to 0.697 for CAs of $17 \cdot 2^{\circ}$ to $99.9^{\circ}$ (Fig. 2(b)). However, high particle attributes did not necessarily equate to high CAs. For instance, the crushed sandstone produced particle attributes of the same range as the sulfides but with lower CAs $\left(>78^{\circ}\right)$ than the sulfides $\left(>120^{\circ}\right)$, while biotite and hematite revealed the opposite. The findings reported by Ulusoy et al. (2003) contradict those shown in Figure 2: Ulusoy et al. (2003) demonstrated that an increase in roundness (similar to sphericity in the current study) was inversely proportional to the wettability of minerals. A possible reason for this disagreement is the wide range of attributes $(0.458$ for hematite and 0.759 for galena) whereas the samples in the work of Ulusoy et al. deviated from a sphere by at most $10 \%$.

Isolation of material chemistry, layer roughness and particle shape effects on CA measurements is a major challenge. Fundamental studies of surface chemistry and surface thermodynamics have long been applied to thin layers of particles attached to a plane glass surface

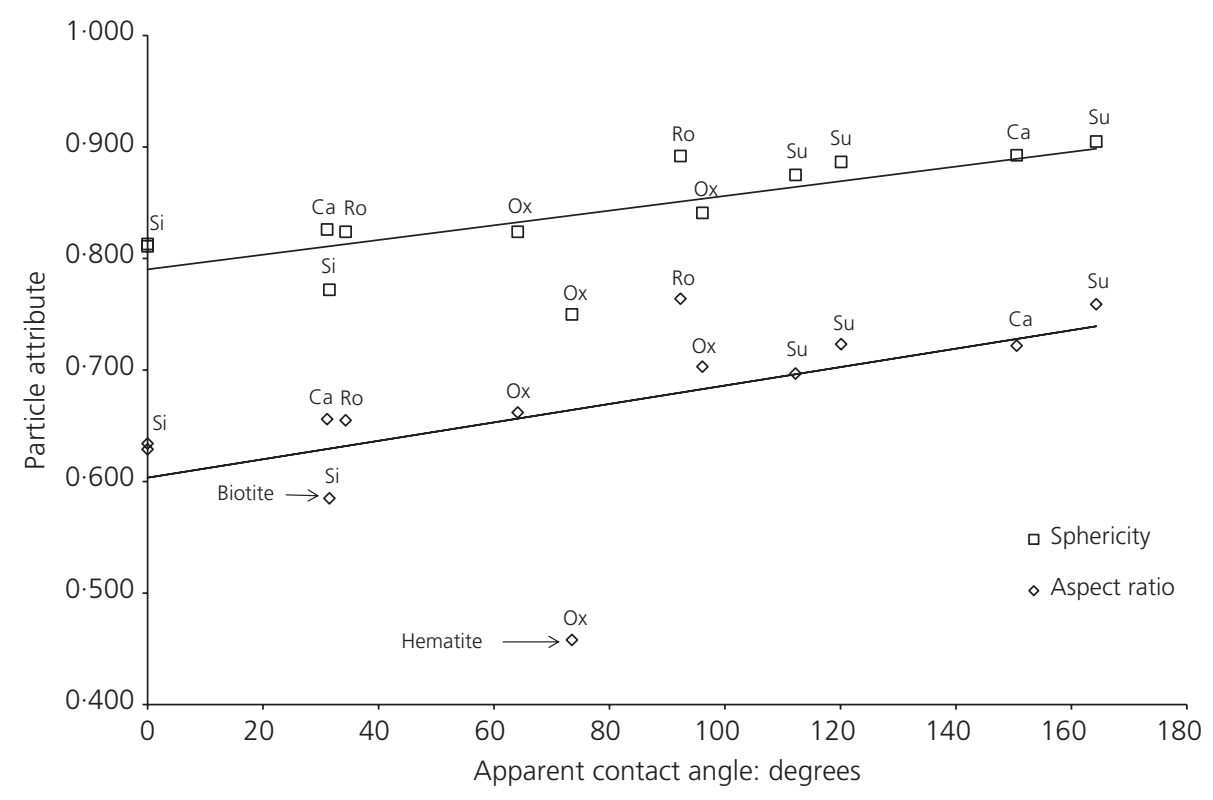

(a)

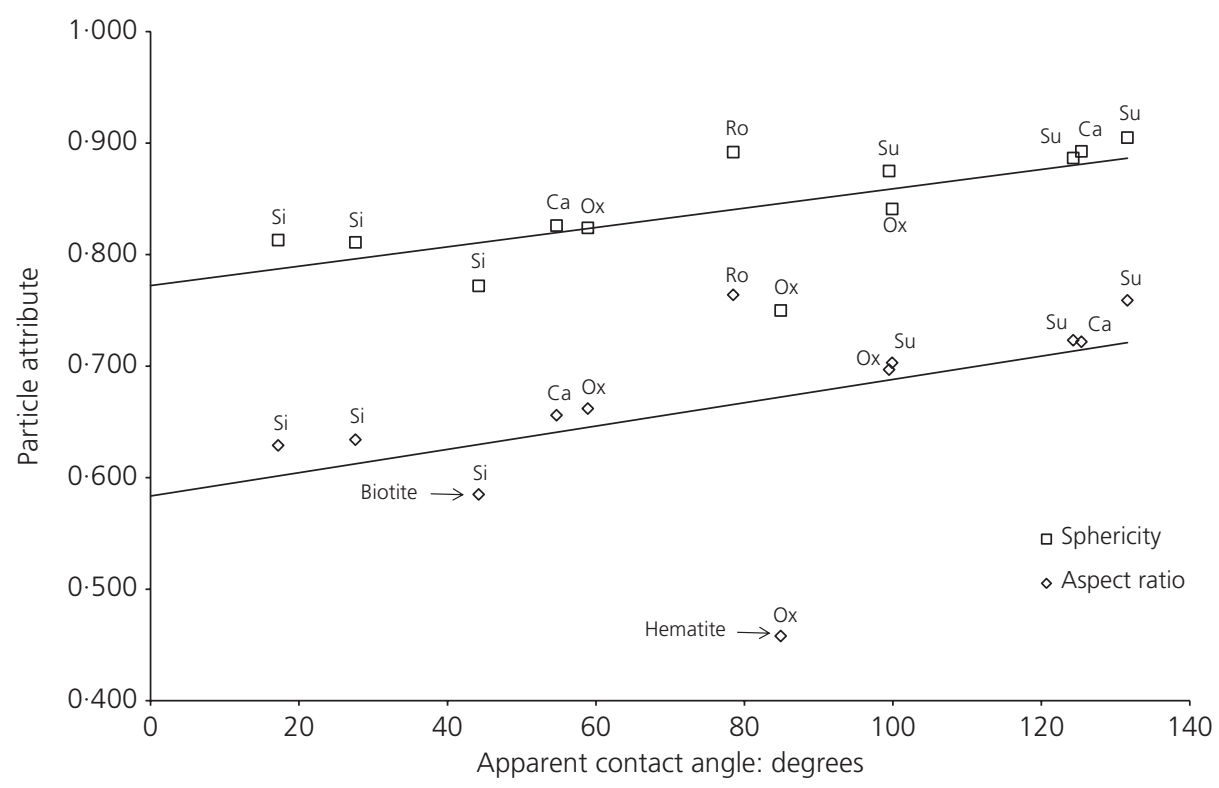

(b)

Fig. 2. Particle sphericity and aspect ratio with respect to (a) WPM CAs and (b) SDM CAs. Su, sulfide minerals; Ca, carbonate minerals; Ox, oxide minerals; $\mathrm{Si}$, silicate minerals; Ro, rock samples (including bauxite) 
(van Oss et al., 1990). Bachmann et al. (2000) proposed fixing soil particles using adhesive tape in order to avoid rearrangement of the particles due to the impact of forces (drop weight, adhesive forces at the three-phase boundary). Model calculations carried out with a combined Wenzel/ Cassie-Baxter approach to take into account the simultaneous impact of roughness, particle packing density and chemical heterogeneity showed that the impact of the tape should not be significant (Bachmann \& McHale, 2009). In addition, other factors influence the $\mathrm{CA}$, such as particle size (CA increases for finer particles) and, since wettability depends on surfaces characteristics, residual water content and deposition of dust. Given these complexities, one approach to validate CAs is to compare measurements from different methods (as done here). The results revealed broad agreement between the SDM and WPM, with the WPM providing higher and lower CAs at the extremes of wettability.

\section{CONCLUSIONS}

The aim of this study was to assess the variability of particle wettability in crushed commonly occurring minerals. The results revealed a wide range of contact angles, with air-dried sulfides and oxides showing water-repellent behaviour. These results suggest that geotechnical processes which generate new surfaces due to particle breakage or abrasion under high stresses (compression or shear) are likely to produce variable surface energies, thus influencing the interaction of the newly formed surfaces with liquids in the post-breakage stage.

\section{ACKNOWLEDGEMENT}

This research was funded by the UK Engineering and Physical Sciences Research Council (EP/K007904/1).

\section{REFERENCES}

Bachmann, J. \& McHale, G. (2009). Superhydrophobic surfaces: a model approach to predict contact angle and surface energy of soil particles. Euro. J. Soil Sci. 60, No. 3, 420-430.

Bachmann, J., Horton, R., van der Ploeg, R. \& Woche, S. (2000). Modified sessile drop method for assessing initial soil-water contact angle of sandy soil. J. Soil Sci. Soc. Am. 64, No. 2, 564-567.

Bachmann, J., Woche, S. K., Göbel, M.-O., Kirkham, M. B. \& Horton, R. (2003). Extended methodology for determining wetting properties of porous media. Water Res. Res. 39, No. 12, 1353-1366.

Bardet, J. P., Jesmani, M. \& Jabbari, N. (2011). Effects of compaction on shear strength of wax-coated sandy soils. Electron. J. Geotech. Engng 16, Bundle D, 451-461.

Bryant, E. M., Bowman, R. S. \& Bucley, J. S. (2006). Wetting alteration of mica surfaces with polyethoxylated amine surfactants. J. Petrol. Sci. Engng. 52, No. 1-4, 244-252.

Byun, Y.-H., Tran, M. K., Yun, T. S. \& Lee, J.-S. (2011). Strength and stiffness characteristics of unsaturated hydrophobic granular media. ASTM Geotech. Test. J. 35, No. 1, 1-8.
Carr, J. S. (1948). Studies of contact angles on oxidized copper minerals. Masters thesis. Missouri University of Science and Technology, Rolla, MO, Paper 4943.

Diehl, D., Schneckenburger, T., Krüger, J. et al. (2014). Effect of multivalent cations, temperature and aging on soil organic matter interfacial properties. Environ. Chem. 11, No. 6, 709-718.

Doerr, S., Shakesby, R. \& Walsh, R. (2000). Soil water repellency: its causes, characteristics and hydro-geomorphological significance. Earth Sci. Rev. 51, No. 1-4, 33-65.

Doerr, S. H., Shakesby, R. A., Dekker, L. W. \& Ritsema, C. J. (2006). Occurrence, prediction and hydrological effects of water repellency amongst major soil and land use types in a humid temperate climate. Eur. J. Soil Sci. 57, No. 5, 741-754.

Fisher, L. R. \& Lark, P. D. (1980). The effect of adsorbed water vapour on liquid water flow in pyrex glass capillary tubes. $J$. Coll. Interf. Sci. 76, No. 1, 251-253.

Gence, N. (2006). Wetting behavior of magnesite and dolomite surfaces. Appl. Surf. Sci. 252, No. 10, 3744-3750.

Goebel, M.-O., Woche, S. K., Abraham, P. M., Schaumann, G. E. \& Bachmann, J. (2013). Water repellency enhances the deposition of negatively charged hydrophilic colloids in a watersaturated sand matrix. Coll. Surf. A: Physicochem. Engng Asp. 431, 150-160.

Hajnos, M., Calka, A. \& Jozefaciuk, G. (2013). Wettability of mineral soils. Geoderma 206, 63-69.

Iveson, S. M., Holt, S. \& Biggs, S. (2004). Advancing contact angle of iron ores as a function of their hematite and goethite content: implications for pelletising and sintering. Int. J. Miner. Proc. 74, No. 1-4, 281-287.

Jarvis, N., Etana, A. \& Stagnitti, F. (2008). Water repellency, near-saturated infiltration and preferential solute transport in a macroporous clay soil. Geoderma 143, 223-230.

Lourenço, S. D. N., Jones, N., Morley, C., Doerr, S. \& Bryant, R. (2015). Hysteresis in the soil water retention of a sand clay mixture with contact angles lower than ninety-degrees. Vadose Zone J. 14, No. 7.

Maeda, T., Fukumoto, C., Matsura, T., Nishioka, K. \& Shimizu, M. (2008). Effect of adding moisture and wettability on granulation of iron ore. ISIJ Int. 45, No. 4, 477-484.

Ma'shum, M., Tate, M., Jones, G. \& Oades, J. (1988). Extraction and characterization of water-repellent materials. J. Soil Sci. 39, No. 1, 99-110.

Prestidge, C. A. \& Ralston, J. (1995). Contact angle studies of galena particles. J. Coll. Interf. Sci. 172, 302-310.

Prestidge, C. A. \& Ralston, J. (1996). Contact angle studies of particulate sulphide minerals. Miner. Engng 9, No. 1, 85-102.

Raichur, A. M., Wang, X. H. \& Parekh, B. K. (2001). Estimation of surface free energy of pyrites by contact angle measurements. Miner. Engng 14, No. 1, 65-75.

Ritsema, C. \& Dekker, L. (1996). Water repellency and its role in forming preferred flow paths in soils. Aust. J. Soil Res. 34, No. 4, 475-487.

Subrahmanyam, T. V., Prestidge, C. A. \& Ralston, J. (1996). Contact angle and surface analysis studies of sphalerite particles. Miner. Engng 8, No. 7, 727-741.

Ulusoy, U., Yekeler, M. \& Yilmaz, C. (2003). Determination of the shape, morphological and wettability properties of quartz and their correlations. Miner. Engng 16, No. 10, 951-964.

van Oss, C. J., Giese, R. F. \& Coslanzo, P. M. (1990). DLVO and non-DLVO interactions in hectorite. Clays Clay Mineral. 38, No. 2, 151-159.

Wadell, H. (1933). Sphericity and roundness of rock particles. J. Geology 41, No. 3, 310-330. 